supposed Roman Mithræum or Mithraic temple discovered on the east bank of the river Medway at Wouldham, near Maidstone. The temple, or "cave," was found by workmen while engaged in removing sand for ballast, and excavated under the superintendence of the exhibitor. It had apparently been built into the bank, standing east and west, measuring 40 feet in length and 20 feet in width. Numerous fragments of tiles, samian and other pottery, animal bones, and a coin of Constantinopolis were found in the filling, but no statuary or inscriptions. So far this "cave" is the only one found south of the river Tyne.

Mr. G. F. Scott Elliot had on view photographs and objects illustrating his recent expedition to Ruwenzori. The photographs showed characteristic trees and shrubs of Taru, view of Kagera River, and of Ruwenzori. The objects consisted of Wandorobbo costume, sword, quiver, fire-stick, and arrows ; Uganda pottery, bark cloths, \&c. ; banana meal, \&c., in form, ready for export.

Mrs. Ellis Rowan exhibited Australian wild flowers in watercolours. The examples were from Northern Queensland and Western Australia.

A letter and original manuscript of Emin Pasha's last Ornithological Journal formed an interesting exhibit by Sir William II. Flower. The objects were found by the officers of the Congo Free State, after Emin had been murdered by the Arabs at Kinena, on or about October 28, 1892 .

A series of cultures of varions forms of the bacteria which had been isolated from the river Thames, and then cultivated by the methods employed in the laboratory, formed Prof Marshall Ward's exhibit. The bacteria were grouped in sections corresponding to the different types, and characterised by differences as to the pigment-production, temperature of growth, capacity of forming spores, behaviour in different media, sizes, shapes, and power of movement, \&c. Some of them belonged to common species; others were rare, or unknown, and not classified.

An instrument for describing parabolas by means of a combined sliding and link motion was exhibited by the inventor, Mr. H. Thomson Lyon.

Sir David Salomons showed new forms of "top" slides for the lantern, selenite and hot-water slide heated electrically; and illustrated the behaviour of a glow lamp in the magnetic field, \&c.

Mr. F. Enock exhibited a living aquatic hymenopterous insect, Polynema natans (Lubbock), Caraphractus cinctus (Haliday), described by him in these columns a few weeks ago. This minute and most beautiful Hymenopteron was observed by Sir John Lubbock swimming or flying under water, crawling about weed, \&c. The Mymarida (Hal.) all oviposit in the eggs of other insects; Polynema natans, according to Ganin, having been bred from eggs of a dragon fly, Asschna. The smallest of this family, Camptoptera papaveris, is but one eightyfifth of an inch in length.

The bone structure in the dentary bone of Gomphognathus, a South African reptile, was illustrated by one of Prof. Seeley's exhibits. The bone structure in this fossil, which is of Permian age, is not distinguishable from the bone structure of a mammal, in the arrangement of the haversian canals and the lacunæ. Prof. Seeley also showed vertical sections through the maxillary and mandibular teeth from the same skull. This exhibit consisted of three vertical sections of the skull of Gomphognathus taken at the hinder termination of the hard palate, showing the conical forms of the single roots to the molar teeth, the flat transverse crowns to the teeth, and the way in which the mandibular teeth are opposed to those in the skuls.

A sacred bone-trumpet, drum, and flute were exhibited by Dr. George Harley. The trumpet and tom-tom drum were from the temple of a Buddhist monastery in Thibet. They were made from the bones of priests-from their being supposed to be more religiously effectual. The trumpet when blown emits a rising and falling mournful wailing sound. The drum, when the knobs attached to its strings are rattled against the skins, gives a disagreeable harsh noise which is thought to drive the evil spirits out of the temple. The flute is a Carib Indian's, from Guiana, made from the tibia of a deer (Coassus rufinus). From it can be got the notes 1,2 , and 3 , in the natural harmonic ratios of 6,7 , and 8 , as in the French flageolet.

The following exhibits, with demonstrations by means of the electric lantern, took place in the meeting-room of the Society.

Lantern slides, illustrating the ethnography of British New Guinea, by Prof. A. C. Haddon. The slides illustrated

$$
\text { NO. I } 338 \text {, VOL. } 52 \text { ] }
$$

the physical characters of different tribes inhabiting British New Guinea, some of the occupations of the people, several kinds of dances, and the distribution of dance-masks. A series of dwellings from one end of the Protectorate to the other was shown, and two types of canoes. Finally, illustrations of the decorative art of various districts were thrown upon the screen. Evidence was given in support of the view that British New Guinea is inhabited by true dark Papuans, and by two distinct lighter Melanesian peoples, one of whom may have come from the New Hebrides, and the other from the Solomon Islands.

Dr. J. Joly exhibited examples of colour photography, and described his method of obtaining them. The photographs were a realisation of composite heliochromy in a single image. The method of composite heliochromy requires three images superimposed by projection. In Dr. Joly's photographs the colour analysis and synthesis are carried out in the one image. The colours are the natural colours as they registered themselves upon the plate, and in no case altered after reproduction. The specimens shown were first attempts, produced with rough apparatus. The images showed a slightly grained appearance, but this is avoidable with proper appliances. The process of taking and reproducing the photographs differs in no way from ordinary photography upon the dry plate, save that the sensitive plate is exposed in the camera behind a screen lined in particular colours. The positive is subsequently viewed through a screen lined with three other colours; the three "fundamental colours," which upon the three-colour theory of vision are supposed to give riseto all our colour sensations.

\section{ON THE TEMPERATURE VARIATION OF}

\section{THE THERMAL CONDUCTIVITY OF ROCKS.'}

$\S \mathrm{I}$. THE experiments described in this communication, were undertaken for the purpose of finding temperature variation of thermal conductivity of some of the more important rocks of the earth's crust.

$\$ 2$. The method which we adopted was to measure, by aid of thermoelectric junctions, the temperatures at different points of a flux line in a solid, kept unequally heated by sources (positive and negative) applied to its surface, and maintained uniform for a sufficiently long time to cause the temperature to be as nearly constant at every point as we could arrange for. The shape of the solid and the thermal sources were arranged to cause the flux lines to be, as nearly as possible, parallel straigh lines; so that, according to Fourier's elementary theory and definition of thermal conductivity, we should have

$$
\frac{k(\mathrm{M}, \mathrm{B})}{k(\mathrm{~T}, \mathrm{M})}=\frac{[v(\mathrm{M})-v(\mathrm{~T})] \div \mathrm{MT}}{[v(\mathrm{~B})-v(\mathrm{M})] \div \overline{\mathrm{BM}}},
$$

where $\mathrm{T}, \mathrm{M}, \mathrm{B}$ denote three points in a stream line (respectively next to the top, at the middle, and next to the bottom in the slabs and columns which we used); $v(\mathrm{~T}), v(\mathrm{M}), v(\mathrm{~B})$ denote the steady temperatures at these points ; and $k(\mathrm{~T}, \mathrm{M}), k(\mathrm{M}, \mathrm{B})$, the mean conductivities between $T$ and $M$, and between $M$ and $\mathrm{B}$ respectively.

$\S 3$. The rock experimented on in each case consisted of two equal and similar rectangular pieces, pressed with similar faces together. In one of these faces three straight parallel grooves are cut, just deep enough to allow the thermoelectric wires and junctions to be embedded in them, and no wider than to admit the wires and junctions (see diagram, $\S 8$ below). Thus, when the two pieces of rock are pressed together, and when heat is so applied that the flux lines are parallel to the faces of the two parts, we had the same result, so far as thermal conduction is concerned, as if we had taken a single slab of the same size as the two together, with long fine perforations to receive the electric junctions. The compound slab was placed with the perforations horizontal, and their plane vertical. Its lower side, when thus placed, was immersed under a bath of tin, kept melted by a lamp below it. Its upper side was flooded over with mercury in our later experiments $(\$ \S 6,7,8)$, as in Hopkins experiments on the thermal conductivity of rock. Heat was carried off from the mercury by a measured quantity of cold water poured upon it once a minute, allowed to remain till the end of a minute, and then drawn off and immediately replaced

1 A paper by Lord Kelvin, P.R.S., and J. R. Erskine Murray, read the Royal Society on May $3^{\circ}$. 
by another equal quantity of cold water. The chief difficulty in respect to steadiness of temperature was the keeping of the gas lamp below the bath of melted tin uniform. If more experiments are to be made on the same plan, whether for rocks or metals, or other solids, it will, no doubt, be advisable to use an automatically regulated gas flame, keeping the temperature of the hot bath in which the lower face of the slab or column is immersed at as nearly constant a temperature as possible, and to arrange for a perfectly steady flow of cold water to carry away heat from the upper surface of the mercury resting on the upper side of the slab or column. It will also be advisable to avoid the complication of having the slab or column in two parts, when the material and the dimensions of the solid allow fine perforations to be bored through it, instead of the grooves which we found more readily made with the appliances available to us.

\$ 4. Our first experiments were made on the slate slab, $25 \mathrm{~cm}$. square and $5 \mathrm{~cm}$. thick, in two halves, pressed together, each $25 \mathrm{~cm}$. by 12.5 , and $5 \mathrm{~cm}$. thick. One of these parts cracked with a loud noise in an early experiment, with the lower face of the composite square resting on an iron plate heated by a powerful gas burner, and the upper face kept cool by ice in a metal vessel resting upon it. The experiment indicated, very decidedly, less conductivity in the hotter part below the middle than in the cooler part above the middle of the composite square slab. We supposed this might possibly be due to the crack, which we found to be horizontal and below the middle, and to be complete across the whole area of $12 \frac{1}{2} \mathrm{~cm}$. by 5 , across which the heat was conducted in that part of the composite slab, and to give rise to palpably imperfect fitting together of the solid above and below it. We therefore repeated the experiment with the composite slab turned upside down, so as to bring the crack in one half of it now to be above the middle, instead of below the middle, as at first. We still found, for the composite slab, less conductivity in the hot part below the middle than in the cool part above the middle. We inferred that, in respect to thermal conduction through slate across the natural cleavage planes, the thermal conductivity diminishes with increase of temperature.

$\$ 5$. We next tried a composite square slab of sandstone of the same dimensions as the slate, and we found for it also decisive proof of diminution of thermal conductivity with increase of temperature. We were not troubled by any cracking of the sandstone, with its upper side kept cool by an ice-cold metal plate resting on it, and its lower side heated to probably as much as $300^{\circ}$ or $400^{\circ} \mathrm{C}$

$\S 6$. After that we made a composite piece, of two small slate columns, each $3.5 \mathrm{~cm}$. square and $6.2 \mathrm{~cm}$. high, with natural cleavage planes vertical, pressed iogether with thermoelectric junctions as before ; but with appliances (see \& Io) for preventing loss or gain of heat across the vertical sides, which the smaller horizontal dimensions $(7 \mathrm{~cm} ., 3 \cdot 5 \mathrm{~cm}$.) might require, but which were manifestly unnecessary with the larger horizontal dimensions $(25 \mathrm{~cm} ., 25 \mathrm{~cm}$.) of the slabs of slate and sandstone used in our former experiments. The thermal flux lines in the former experiments on slate were perpendicular to the natural cleavage planes, but now, with the thermal flux lines parallel to the cleavage planes, we still find the same result, smaller thermal conductivity at the higher temperatures. Numerical results will be stated in $\S \mathrm{I} 2$ below.

$\S 7$. Our last experiments were made on a composite piece of Aberdeen granite, made up of two columns, each $6 \mathrm{~cm}$. high and $7.6 \mathrm{~cm}$. square, pressed together, with appliances similar to those described in $\$ 6 ;$ and, as in all our previous experiments on slate and sandstone, we found less thermal conductivity at higher temperatures. The numerical results are given in $\$ I 2$.

\$ 8 . The accompanying diagram (Fig. $x$ ) represents the thermal appliances and thermoelectric arrangement of $\$ \S 6,7$. The columns of slate or granite were placed on supports in a bath of melted tin with about $0.2 \mathrm{~cm}$. of their lower ends immersed.

$$
\text { NO. I } 338 \text {, VOL. 52] }
$$

The top of each column was kept cool by mercury, and water changed once a minute, as described in $\S 3$ above, contained in a tank having the top of the stone.column for its bottom, and completed by four vertical metal walls fitted into grooves in the stone, and made tight against wet mercury by marine glue.

\& 9. The temperatures $v(\mathrm{~B}), v(\mathrm{M}), v(\mathrm{~T})$ of $\mathrm{B}, \mathrm{M}, \mathrm{T}$, the hot, intermediate, and cool points in the stone, were determined by equalising to them successively the temperature of the mercury thermometer placed in the oil-tank, by aid of thermoelectric circuits and a galvanometer used to test equality of temperature by nullity of current through its coil when placed in the proper circuit, all as shown in the diagram. The steadiness of temperature in the stone was tested by keeping the temperature of the thermometer constant, and observing the galvanometer reading for current when the junction in the oil-tank and one or other of the three junctions in the stone were placed in circuit. We also helped ourselves to attaining constancy of temperature in the stone by observing the current through the galvanometer, due to differences of temperature between any two of the three junctions $\mathrm{B}, \mathrm{M}, \mathrm{T}$ placed in circuit with it.

$\S$ ro. We made many experiments to test what appliances might be necessary to secure against gain or loss of heat by the stone across its vertical faces, and found that kieselguhr, loosely packed round the columns and contained by a metal ease surrounding them at a distance of $2 \mathrm{~cm}$. or $3 \mathrm{~cm}$., prevented any appreciable disturbance due to this cause. This allowed us to feel sure that the thermal flux lines through the stone were very

G. I.- Iron wires are marked $i$. Platinoid wires are marked $\not ., \quad \mathrm{B}, \mathrm{M}, \mathrm{T}$. Thermoelectric junctions in Thermoelectric junctions in oil bath. A. Bath of molten tin. C. Tank of cold water. D. ins shall depend solely on differences of temperature between whatever two of the four junctions, $\mathrm{X}, \mathrm{T}, \mathrm{M}, \mathrm{B}$, is put in circuit with the galvanometer. G. Galvanometer. H. Four mercury cups, for convenience in connecting the galvanometer to any pair of thermoelectric junctions. $x, b, m, t$, are connected, through copper and platinoid, with $\mathrm{X}, \mathrm{B}, \mathrm{M}, \mathrm{T}$, respectively.

approximately parallel straight lines on all sides of the central line BMT.

\& I I. The thermometer which we used was one of Casella's (No. 64, I68) with Kew certificate (No. 48,47 I) for temperature from $0^{\circ}$ to $100^{\circ}$, and for equality in volume of the divisions above $100^{\circ}$. We standardised it by comparison with the constant volume air thermometer ${ }^{1}$ of Dr. Bottomley with the following result. This is satisfactory as showing that when the zero error is corrected the greatest error of the mercury thermometer, which is at $211^{\circ} \mathrm{C}$, is only $03^{\circ}$.

\begin{tabular}{|c|c|c|c|c|c|}
\hline $\begin{array}{l}\text { Air } \\
\text { thermometer. }\end{array}$ & & $\begin{array}{c}\text { Mercury } \\
\text { thermometer. }\end{array}$ & & from & $\begin{array}{l}\text { to be } \\
\text { ing of } \\
\text { rmom }\end{array}$ \\
\hline$\stackrel{\circ}{\circ}$ & $\ldots$ & I.9 9 & .. & $\cdots$ & $1 \bullet 9$ \\
\hline $120^{\circ} 2$ & $\cdots$ & $122 \cdot 2$ & $\cdots$ & ... & $2 \circ 0$ \\
\hline $166.8 \ldots$ & $\ldots$ & $168 \cdot 6$ & $\ldots$ & $\ldots$ & $1 \cdot 8$ \\
\hline $2 I I \cdot I \quad .$. & $\cdots$ & 2127 & $\ldots$ & $\cdots$ & I.6 \\
\hline $265^{\circ} 7$ & $\ldots$ & $267 \times 5$ & $\ldots$ & $\ldots$ & $1 \cdot 8$ \\
\hline
\end{tabular}

1 Phil. Mag., August r888, and Roy. Soc. Edin. Proc., January 6, 1888 . 
\$ 12. Each experiment on the slate and granite columns lasted about two hours from the first application of heat ind cold ; and we generally found that after the first hour we could keep the temperatures of the three junctions very nearly constant. Choosing 'a time of best constancy in our experiments on each of the two substances, slate and granite, we found the following results :-

Slate : flux lines parallel to cleavage.

$$
\begin{aligned}
& v(\mathrm{~T})=50^{\circ} \cdot 2 \mathrm{C} . \\
& v(\mathrm{M})=123^{\circ} \cdot 3 . \\
& v(\mathrm{~B})=202^{\circ} \cdot 3 .
\end{aligned}
$$

The distances between the junctions were $B M=2.57 \mathrm{~cm}$. and $M T=2.6 \mathrm{~cm}$. Hence by the formula of $\S 2$,

$$
\frac{k(\mathrm{M}, \mathrm{B})}{k(\mathrm{~T}, \mathrm{M})}=\frac{73 \cdot 1 \div 2 \cdot 6}{79.0 \div 2.57}=\frac{28 \cdot 1}{30 \cdot 7}=0.91 \text {. }
$$

Aberdeen granite :

$$
\begin{aligned}
& v(\mathrm{~T})=81^{\circ} \cdot 1 . \\
& v(\mathrm{M})=145^{\circ} \cdot 6 . \\
& v(\mathrm{~B})=214^{\circ} \cdot 6 .
\end{aligned}
$$

The distances between the junctions were $\mathrm{BM}=\mathrm{I} \cdot 9 \mathrm{~cm}$. and $M T=2 \cdot 0 \mathrm{~cm}$.

$$
\frac{k(\mathrm{MB})}{k(\mathrm{TM})}=\frac{64 \cdot 5 \div 2 \cdot 0}{69 \cdot 0 \div 1} \cdot \frac{32 \cdot 2}{36 \cdot 3}=0.88
$$

\& 13. Thus we see, that for slate, with lines of flux parallel to cleavage planes, the mean conductivity in the range from $123^{\circ} \mathrm{C}$. to $202^{\circ} \mathrm{C}$. is $9 \mathrm{r}$ per cent. of the mean conductivity in the range from $50^{\circ} \mathrm{C}$. to $123^{\circ} \mathrm{C}$, and for granite, the mean conductivity in the range from $145^{\circ} \mathrm{C}$. to $2 \mathrm{I} 4^{\circ} \mathrm{C}$. is 88 per cent. of the mean conductivity in the range from $8 \mathrm{I}^{\circ} \mathrm{C}$. to $145^{\circ} \mathrm{C}$. The general plan of apparatus, described above, which we have used only for comparing the conductivities at different temperatures, will, we believe, be found readily applicable to the determination of conductivities in absolute measure.

\section{THE RELATION BETWEEN THE MOVE}

\section{MENTS OF THE EYES AND THE MOVE MENTS OF THE HEAD. ${ }^{1}$}

$W^{\mathrm{E}}$ all know that it was a long time before mankind found out that the earth moves. For ages the apparent motion of the heavenly bodies was supposed to be their real motion, the earth being fixed. We, who know something of the truth in this matter, do not, however, any more than our ancestors did, see or feel the earth move. We believe that it does so either because we have been told by some one who, we think, knows about such things, or because we have reasoned the matter our from data observed by ourselves or reported by credible observers. But in habitual thought and speech we go back to the old assumption which, for our practical, terrestrial purposes, answers well enough, and is perfectly in accordance with our sensations.

When we turn from the great Cosmos to the microcosm; when we compare the motion of our own body among the various fixed (terrestrially fixed) and moving bodies around us, with the motion of the earth among the stars, we find quite a different state of matters. It never occurs to us that our own body is at rest, and that the trees, houses, \&c., move. When we really move we not only know, but feel and see that we are moving, and every one learned or ignorant, old or young-if only he is sober-feels and sees that the solid earth is fixed, except on the rare occasion of an earthquake, and in the case of some illusions which we shall have to consider. I wish to discuss the cause of this sensation of the fixedness of the earth, and also incidentally of the exception implied in the words I have just used, "if only he is sober."

If we keep our head fixed and look at any really fixed scene -say, a room in which there is nothing moving-or a landscape, if we can find one without railway trains, ships, moving beasts, or flying birds, we can allow our eyes to run over it in as uniform or as irregular a way as we please, and see that the scene remains fixed. We might have supposed that, as we move our eyes

2 Being the Fourth " Robert Boyle" Lecture, delivered before the Oxford University Junior Scientific. Club, at the Universitv Museum, Oxford, on May 13, 1895, by Prof. A. Crum Brown, F.R.S.

$$
\text { No. } 1338 \text {, rol. } 52]
$$

from right to left the whole scene, like a moving panorama, would seem to move from left to right, but it does not do so. It remains visibly at rest, and we know, without any reasoning about it, that the changes of view were produced by the motion of our eyes.

We fancy that we can move our eyes uniformly, that by a continuous motion like that of a telescope we can move our eyes along the sky-line in the landscape or the cornice of the room, but we are wrong in this. However determinedly we try to do so, what actually happens is, that our eyes move like the seconds hand of a watch, a jerk and a little pause, another jerk and so on ; only our eyes are not so regular, the jerks are sometimes of greater, sometimes of less, angular amount, and the pauses vary in duration, although, unless we make an effort, they are always short. During the jerks we practically do not see at all, so that we have before us not a moving panorama, but a series of fixed pictures of the same fixed things, which succeed one another rapidly. It is not difficult to understand how this gives rise to a sensation of the fixedness of the external scene. If, in the otherwise fixed scene, there is a really moving object, we see it move, because during the pauses, short as they are, the moving object has visibly changed its place, and in each of our fixed pictures the moving object is seen to move. If it moves too slowly for this. then we do not see it move, but only infer its motion from comparison of its position at different times. If we keep our eyes fixed on the moving object, and this is possible if it does not move too fast or too irregularly, then we see it fixed and the really fixed things moving, an illusion we have all observed when the pier seems to move and the steamer remain at rest.

That the eyes jerk in the way now stated can be made plain by means of a simple experiment. If we have in the field of view a bright object, such as an incandescent electric lamp, and after running our eyes over the scene before us, shut our eyes, we see secondary images of the bright object. ${ }^{1}$ Now if the eyes move continuously from one position to another, we should see between the two secondary images of the bright object corresponding to these two pasitions, a bright band composed of an infinite number of images each infinitely near its two neighbours. But we see no, such band, but a finite number of sharp individual images, each of which corresponds to the position of the eyes during a pause between jerks; unless the bright object is very bright, there is nothing in the secondary image to represent the positions of the eyes during the jerk. If for a bright object we take the sun, then we do see bands joining the sharp secondary images. These bands are fainter than the sharp images, and die away sooner, They are the impressions made on the retina by the image of the sun passing rapidly across it during the jerk. But, if with the fixed bright object in the field we follow with our/ eyes a really moving thing, then on shutting the eyes we see a band of light, because the image of the bright object passed not very rapidly across the retina.

This habit of jerking the eyes from one position of vision to another, as fast as the light, well-poised globes can be swung round by the quick-working, straight-fibred muscles which move them, may be an innate habit, or it may have been acquired by our looking at things and turning quickly from one object of interest to another; at all events, it is now the way in which alone we can move them; unless we fix them on a moving object.

So far I have supposed the head fixed and the eyes alone moving. Let us now attend to what happens when we move our head. ${ }^{2}$

The movement of the head, unless it is very rapid, makes no difference at all in the phenomena just described.

If we call the line along which we look during the pause between the two jerks a glance-line, we may describe the whole phenomenon by saying that the glance-lines are fixed relatively to fixed external objects, whether the head is rotated or not. This, of course, means that, during a pause, the eyes are rotated relatively to the head about the axis about which the head is really rotated, in the opposite sense and through the same angle as the head.

It might, for all that has been yet said, be supposed that this fixedness of the glance-lines, when the head is rotated, depends on the habit of looking at things; but that this is not the cause, or, at all events, not the only cause, is plain from the fact that the same relative movements of the eyes take place when we

1 The secondary images are better seen if we look at a white surface and wink rapidly.

¿ By "moving the head," I mean moving the head either alone or along with the body or any part of it. 